\title{
The Pathophysiology of Hereditary Angioedema
}

\author{
Bruce L. Zuraw, MD
}

\begin{abstract}
Hereditary angioedema (HAE) causes recurrent episodes of angioedema that may be very severe and are frequently associated with significant morbidity and even mortality. Understanding the pathophysiology of this disease is crucial for proper diagnosis and management of these patients. HAE is caused by mutations in the SERPING1 gene that result in decreased plasma levels of functional $\mathrm{C} 1$ inhibitor. A large number of different mutations have been described that result in HAE. About $15 \%$ of patients have a mutation at or near the active site of the reactive mobile loop, resulting in a protein that lacks functional activity (type II HAE). Type I HAE is caused by a diverse range of mutations, some of which cause the nascent protein to misfold and thus to be unable to enter the secretory pathway. The primary mediator of swelling in HAE is bradykinin, a product of the plasma contact system. Bradykinin induces increased vascular permeability by activating the bradykinin B2 receptor, which results in phosphorylation of vascular endothelial cadherin. The regulation of both the bradykinin B2 receptor and peptidases that degrade bradykinin may influence HAE disease severity. HAE results from mutations in the SERPING1 gene that lead to a loss of functional $\mathrm{C} 1$ inhibitor. Attacks of angioedema result from generation of bradykinin, which acts on bradykinin B2 receptors to enhance vascular permeability.
\end{abstract}

Key Words: HAE, C1 inhibitor, contact system, bradykinin, plasma kallikrein, Hageman factor

(WAO Journal 2010; 3:S25-S28)

n 1888, William Osler described a familial form of angioedema associated with significant morbidity and mortality. ${ }^{1}$ $\mathrm{He}$ called this disease hereditary angio-neurotic edema (HANE), a name that has subsequently been shortened to hereditary angioedema (HAE). The prevalence of HAE is not known for certain, but has been estimated to range from $1: 30,000$ to $1: 80,000$ in the general population without any known sex, ethnic, or racial differences. ${ }^{2}$

HAE is clinically characterized by recurrent episodes of angioedema that typically involve the extremities, gastroin-

From the Department of Medicine, University of California San Diego and San Diego Veteran's Affairs Medical Center, La Jolla, Cal.

Presented as part of "New Perspectives in Hereditary Angioedema: Molecular Mechanisms and Therapeutic Choices", a CME Symposium presented at the 2009 World Allergy Congress, Buenos Aires, Argentina, December 9, 2009 .

Correspondence to: Bruce Zuraw, MD, 9500 Gilman Drive, Mailcode 0732, La Jolla, CA 92093-0732.

Telephone: 858-822-6597. Fax: 858-642-3791. E-mail: bzuraw@ucsd.edu. Copyright (C) 2010 by World Allergy Organization testinal tract, face, oropharynx, larynx, or external genitalia. Patients with HAE experience discrete episodes of nonpruritic nonpitting angioedema at these sites. ${ }^{2,3} \mathrm{HAE}$ attacks are classically distinguished from allergic or idiopathic angioedema by their longer duration (typically 72-96 hours), absence of accompanying urticaria and failure to respond to antihistamines or corticosteroid therapy.

Most often, patients with HAE become symptomatic during childhood. Fifty percent of HAE patients first experience a swelling episode before age 10, with some patients manifesting angioedema as early as 1 year of age..,5 Most patients then experience a worsening of symptoms around puberty. ${ }^{3}$ Occasionally, patients with HAE do not begin to show evidence of angioedema until their late teens or early adulthood. Rare patients with HAE have been reported who never experience angioedema, but are identified through screening family members of a symptomatic patient. ${ }^{5,6} \mathrm{Al}-$ though some patients seem to experience decreased symptoms as they age, other patients continue to experience HAE attacks throughout their lives.

This article will address 4 questions that will help illuminate the clinical issues described above: 1) What is the underlying basis of HAE? 2) Why do patients become C1 inhibitor deficient? 3) What is the primary mediator of swelling in HAE? and 4) What is the molecular basis of bradykinin-induced swelling?

\section{WHAT IS THE UNDERLYING BASIS OF HAE?}

The pathophysiologic basis of HAE as a deficiency of a plasma inhibitor was discovered in the early 1960s. Landerman et al reported that patients with HAE lacked an inhibitor of serum globulin permeability factor (shown subsequently to be activated Hageman factor) or plasma kallikrein. ${ }^{7}$ The next year, Donaldson and Evans, in a seminal publication, identified the missing inhibitor as $\mathrm{C} 1$ inhibitor. ${ }^{8}$ The identification of $\mathrm{C} 1$ inhibitor deficiency as the basis of HAE allowed the pathophysiologic and molecular mechanisms of HAE to be explored.

C1 inhibitor is a broad-spectrum serine protease inhibitor that is a member of the serpin (serine protease inhibitor) superfamily, with significant homology to $\alpha 1$-antitrypsin. It is the major inhibitor of several complement proteases (C1r, C1s, MASP-1, and MASP-2) and contact system proteases (plasma kallikrein and activated Hageman factor [coagulation factors XIIa and XIIf] $).{ }^{9} \mathrm{C} 1$ inhibitor is also an inhibitor of the fibrinolytic protease plasmin and the coagulation protease factor XIa.

Like other serpins, C1 inhibitor functions as a "molecular mousetrap," undergoing large scale rearrangement and 
trapping the target protease when it is cleaved. ${ }^{10} \mathrm{C} 1$ inhibitor is a suicide inhibitor, forming a 1:1 stoichiometric complex with the target protease, which is followed by clearance of the entire complex. In cases of overwhelming proteolytic activation, $\mathrm{C} 1$ inhibitor can be cleaved into a modified inactive form without forming a complex with or inhibiting the protease. ${ }^{11}$

The 2.1-kb C1 inhibitor cDNA was initially cloned and sequenced in $1986 .{ }^{12} \mathrm{C} 1$ inhibitor is a $110-\mathrm{kD}$ single-chain glycoprotein consisting of 478 amino acids plus a 22-residue signal peptide. ${ }^{12}$ The protein is organized into 2 domains: the N-terminal 100 amino acids contain the $\mathrm{N}$ - and O-linked carbohydrates, and the C-terminal 378 amino acids contain the active site in a stressed loop conformation typical of the serpins. ${ }^{12}$ The 17,159-basepair genomic sequence of the gene was published in $1991 .{ }^{13}$ The gene, now named SERPING1, is located on chromosome 11 (p11.2-q13), contains 8 exons and 7 introns, does not contain a $5^{\prime}$ TATA box, and is distinguished by $17 \mathrm{Alu}$ repeats in introns 3 to 7 . More recently, the crystal structure has been solved. ${ }^{14}$

The $\mathrm{C} 1$ inhibitor deficiency in HAE has been shown to result from mutations of the SERPING1 gene. A large number of SERPING1 mutations have been identified, ,9,15-18 with additional mutations still being reported. A database tabulating known SERPING1 gene mutations (http://hae.enzim.hu) currently lists more than 150 different mutations identified in patients with HAE.

The autosomal dominant pattern of HAE was recognized by Osler in $1888 .{ }^{1}$ Each child of an affected patient has a $50 \%$ chance of having HAE. Importantly, HAE does not skip generations. Lack of a positive family history of angioedema cannot, however, be used to exclude the diagnosis. Although $\sim 75 \%$ of patients give a history of having an affected parent, the remaining $25 \%$ of patients presumably have a de novo mutation of the $\mathrm{C} 1$ inhibitor gene that results in HAE. ${ }^{19}$

\section{WHY DO PATIENTS BECOME C1 INHIBITOR DEFICIENT?}

Two different forms of HAE associated with low $\mathrm{C} 1$ inhibitor function have been identified. ${ }^{20}$ Type I HAE is the most common form, accounting for about $85 \%$ of cases. It is associated with decreased antigenic levels of $\mathrm{C} 1$ inhibitor in the plasma. A large number of different SERPING1 mutations have been associated with type I HAE, including missense, nonsense, frameshift, deletion, and insertion mutations. In general, type I HAE is caused by mutations in the $\mathrm{C} 1$ inhibitor gene that result in either truncated proteins or misfolded proteins that cannot be secreted. ${ }^{21}$

This failure of some type I C1 inhibitor mutant proteins to be efficiently secreted is presumably because of a failure of the mutant protein to correctly fold into the native $\mathrm{C} 1$ inhibitor structure. Newly synthesized proteins are cotranslationally translocated from the ribosome into the endoplasmic reticulum (ER), where they must fold into a native conformation before they are able to exit to the Golgi apparatus. Protein folding has been shown to follow a thermodynamic gradient in which the most stable or native conformation lies at a free energy minimum, ${ }^{22}$ and specialized ER proteins (chaperones and folding enzymes) interact with the nascent protein, helping it to fold correctly and avoid kinetic traps until it reaches native conformation. If the protein fails to reach this conformation, it is no longer targeted for secretion; instead, it is retrotranslocated back into the cytosol for degradation in the proteasome. ${ }^{23}$

Approximately another $15 \%$ of HAE patients have type II HAE. This type of HAE is characterized by normal plasma antigenic levels of $\mathrm{C} 1$ inhibitor but decreased functional levels of the plasma C1 inhibitor. ${ }^{20,24}$ Most of SERPING1 mutations associated with type II HAE involve residues at or near the active site on the reactive mobile loop that result in a mutant $\mathrm{C} 1$ inhibitor protein that is secreted but is dysfunctional. ${ }^{25}$

In both type I and type II HAE, the low functional level of $\mathrm{C} 1$ inhibitor results in diminished regulation of the complement and contact systems. Because C1 inhibitor functions as a suicide inactivator, every molecule of $\mathrm{C} 1 \mathrm{r}, \mathrm{C} 1 \mathrm{~s}$, plasma kallikrein, or factor XIIa that is inhibited consumes a molecule of $\mathrm{C} 1$ inhibitor. Because of the reduced function of $\mathrm{C} 1$ inhibitor in HAE, turnover of the $\mathrm{C} 1$ inhibitor may be higher in patients with HAE. ${ }^{26}$ Clearance of radiolabeled $\mathrm{C} 1$ inhibitor appears to support this hypothesis, ${ }^{27}$ although pharmacokinetic analyses of infused $\mathrm{C} 1$ inhibitor concentrates have not confirmed the evidence of more rapid turnover of $\mathrm{C} 1$ inhibitor in HAE patients. This is an area that will require more information.

\section{WHAT IS THE PRIMARY MEDIATOR OF SWELLING IN HAE?}

Identification of the mediator of swelling in patients with HAE has important implications for developing more effective treatments for the disease. Incubation of plasma from $\mathrm{HAE}$ patients ex vivo at $37^{\circ} \mathrm{C}$ generates a factor that causes smooth muscle contraction and increased vascular permeability. ${ }^{28}$ It was quickly recognized that this vascular permeability enhancing factor was likely to be the mediator of swelling in HAE; however, the identity of this factor was an area of significant controversy for many years. C1 inhibitor is a major inhibitor of several complement proteases and contact system proteases. During HAE attacks, each of these plasma proteolytic cascades is activated and several vasoactive substances are potentially generated. From these considerations, 2 potential mediators of swelling in HAE were identified: C2 kinin, generated through activation of the classic complement pathway, ${ }^{29}$ and bradykinin, generated through activation of the contact system. ${ }^{30}$

Over time, compelling laboratory and clinical data have demonstrated that bradykinin is the primary mediator that enhances vascular permeability in HAE. ${ }^{11,30-39}$ Bradykinin is a nanopeptide generated by activation of the contact system. In this system, active plasma kallikrein cleaves high-molecular-weight kininogen to release bradykinin. The generated bradykinin can potently increase vascular permeability by binding to its cognate receptor (the $\mathrm{B} 2$ bradykinin receptor) on vascular endothelial cells. Active plasma kallikrein has been detected in the blister fluid of HAE patients but not in 
that of normal controls. ${ }^{30}$ Incubation of HAE plasma ex vivo was shown to generate bradykinin. ${ }^{31,32}$ Furthermore, the contact system is activated in vivo during attacks of angioedema in HAE patients, ${ }^{33-35}$ and increased levels of bradykinin have been measured in plasma during attacks of angioedema. ${ }^{36}$

Contact system activation was also shown to cleave $\mathrm{C} 1$ inhibitor into a nonfunctional form, ${ }^{11}$ and the plasma level of cleaved nonfunctional $\mathrm{C} 1$ inhibitor is increased during attacks of angioedema in HAE patients. ${ }^{37}$ Importantly, the activity to enhance vascular permeability that is generated by ex vivo incubation of $\mathrm{C} 1$ inhibitor-deficient plasma was shown to be independent of $\mathrm{C} 2$ but completely dependent on high-molecular-weight kininogen (the substrate for bradykinin). ${ }^{38} \mathrm{C} 1$ inhibitor knockout mice show a persistent increase in vascular permeability, which can be corrected by administration of exogenous $\mathrm{C} 1$ inhibitor. ${ }^{39}$ Additionally, the vascular permeability defect depends on both plasma kallikrein activity and bradykinin receptor signaling. ${ }^{39}$ In view of the overwhelming evidence supporting the predominant role of bradykinin as the mediator of swelling in HAE and the absence of substantiating evidence for a kinin derived from $\mathrm{C} 2,32,38$ it was of little surprise that drugs targeting bradykinin generation or action have shown efficacy in clinical trials for treatment of acute attacks of angioedema in HAE. ${ }^{40,41}$

\section{WHAT IS THE MOLECULAR BASIS OF BRADYKININ-INDUCED SWELLING?}

With the demonstration that bradykinin is the mediator of swelling in HAE, more attention has been paid to the mechanisms that influence the ability of bradykinin to induce angioedema. In particular, the catabolism of bradykinin, the expression of bradykinin receptors, and the signaling events that result in swelling need to be considered.

Bradykinin is catabolized by a variety of peptidases (also called kininases). The most important peptidase in the catabolism of bradykinin is angiotensin converting enzyme (ACE); other important peptidases involved in the metabolism of bradykinin include aminopeptidase P (APP), carboxypeptidase $\mathrm{N}$, neutral endopeptidase, and dipeptidyl peptidase IV. ${ }^{42,43}$ Decreasing activity of these peptidases (such as by using an ACE inhibitor) can increase the half-life of bradykinin and potentially worsen HAE disease severity. Decreased levels of APP have been detected in patients on ACE inhibitors who develop angioedema. ${ }^{44}$ Interestingly, long-term prophylaxis treatment of HAE with danazol results in increased APP activity, ${ }^{45}$ suggesting that long-term prophylaxis therapy with danazol may improve symptoms, in part, by increasing bradykinin catabolism.

Bradykinin is a pluripotent nanopeptide that mediates a variety of physiologic and pathologic effects (reviewed in ${ }^{46}$ ). Binding of bradykinin to the bradykinin B2 receptor on vascular endothelial cells results in a marked increase in microvascular permeability. Lung et $\mathrm{al}^{47}$ reported that HAE clinical severity is influenced by a polymorphism in the noncoding first exon of the bradykinin B2 receptor that affects bradykinin B2 receptor expression. Although a subsequent study failed to observe this pattern in a different cohort, ${ }^{48}$ other studies have confirmed the role of this polymor- phism in modulating bradykinin actions. ${ }^{49,50}$ Additionally, a recent report suggested that the permeability enhancement in HAE attacks may be transduced by a combination of bradykinin $\mathrm{B} 2$ receptors and induced bradykinin B1 receptors. ${ }^{51}$

The mechanism by which bradykinin enhances vascular permeability is thought to primarily involve its effects on the phosphorylation of vascular endothelial cell cadherin (VEcadherin). VE-cadherin is the key protein involved in the formation of endothelial tight junctions, which regulate water movement across the endothelial layer. Bradykinin activates phospholipase-C, leading to increases in intracellular calcium and diacylglycerol (DAG), and activating protein kinase C. Protein kinase $\mathrm{C}$ phosphorylates beta-catenin and leads to the internalization and destruction of the VE-cadherin; it is also involved in the generation of the vasodilator nitric oxide. ${ }^{52}$ Activated protein kinase $\mathrm{C}$ also phosphorylates myosin light chain kinase, promoting actin cytoskeleton contraction. Therefore, bradykinin causes the glue between the cells to disappear and causing the cells to centripetally contract. The net effect of this is to increase the gap between vascular endothelial cells, allowing water to move from the vascular space into the tissue. Clinically, this is angioedema.

In conclusion, HAE results from mutations in the SERPING1 gene, leading to production of a mutant $\mathrm{C} 1$ inhibitor protein that is either not secreted (type I HAE) or dysfunctional (type II HAE). The lack of sufficient functional C1 inhibitor in plasma to adequately inhibit the contact system proteases plasma kallikrein and coagulation factor XIIa results in increased generation of bradykinin, which acts on bradykinin B2 receptors to enhance vascular permeability.

\section{ACKNOWLEDGEMENT}

This CME satellite symposium was kindly supported by an educational grant from ViroPharma Incorporated, and sponsored by the World Allergy Congress 2009 and Robert Michael Educational Institute LLC. In addition, the authors and editors would like to thank Naomi Ruff, PhD, for her editorial contribution.

\section{REFERENCES}

1. Osler W. Hereditary angio-neurotic oedema. Am J Med Sci. 1888;95: 362-367.

2. Zuraw BL. Clinical practice. Hereditary angioedema. $N$ Engl J Med. 2008;359:1027-1036.

3. Frank MM, Gelfand JA, Atkinson JP. Hereditary angioedema: the clinical syndrome and its management. Ann Intern Med. 1976;84:586593.

4. Farkas H, Varga L, Szeplaki G, Visy B, Harmat G, Bowen T. Management of hereditary angioedema in pediatric patients. Pediatrics. 2007; 120:e713-e722.

5. Agostoni A, Cicardi M. Hereditary and acquired C1-inhibitor deficiency: biological and clinical characteristics in 235 patients. Medicine (Baltimore). 1992;71:206-215.

6. Molina C, Brun J, Coulet M, Betail G, Wahl D, Hartmann L. Diagnostic and therapeutic problems associated with hereditary deficiency of the $\mathrm{C} 1$ esterase inhibitor. Clin Allergy. 1977;7:127-135.

7. Landerman NS, Webster ME, Becker EL, Ratcliffe HE. Hereditary angioneurotic edema. II. Deficiency of inhibitor for serum globulin permeability factor and/or plasma kallikrein. J Allergy. 1962;33:330 341 .

8. Donaldson VH, Evans RR. A biochemical abnormality in hereditary angioneurotic edema: absence of serum inhibitor of C'1-esterase. Am J Med. 1963;35:37-44. 
9. Davis AE III. C1 inhibitor and hereditary angioneurotic edema. Annu Rev Immunol. 1988;6:595-628.

10. Lomas DA, Belorgey D, Mallya M, Miranda E, Kinghorn KJ, et al. Molecular mousetraps and the serpinopathies. Biochem Soc Trans. 2005;33(Pt 2):321-330.

11. Zuraw BL, Curd JG. Demonstration of modified inactive first component of complement (C1) inhibitor in the plasmas of $\mathrm{C} 1$ inhibitor-deficient patients. JCI. 1986;78:567-575.

12. Bock SC, Skriver K, Nielsen E, Thøgersen HC, Wiman B, et al. Human C1 inhibitor: primary structure, cDNA cloning, and chromosomal localization. Biochemistry. 1986;25:4292-4301.

13. Carter PE, Duponchel C, Tosi M, Fothergill JE. Complete nucleotide sequence of the gene for human $\mathrm{C} 1$ inhibitor with an unusually high density of Alu elements. Eur J Biochem. 1991;197:301-308.

14. Beinrohr L, Harmat V, Dobo J, Lorincz Z, Gal P, Zavodszky P. C1 inhibitor serpin domain structure reveals the likely mechanism of heparin potentiation and conformational disease. J Biol Chem. 2007;282: 21100-21109.

15. Bissler JJ, Aulak KS, Donaldson VH, Rosen FS, Cicardi M, Harrison RA, Davis AE 3rd. Molecular defects in hereditary angioneurotic edema. Proc Assoc Am Physicians. 1997;109:164-173.

16. Verpy E, Biasotto M, Brai M, Misiano G, Meo T, Tosi M. Exhaustive mutation scanning by fluorescence-assisted mismatch analysis discloses new genotype-phenotype correlations in angiodema [see comments]. Am J Hum Genet. 1996;59:308-319.

17. Zuraw BL, Herschbach J. Detection of $\mathrm{C} 1$ inhibitor mutations in patients with hereditary angioedema. J Allergy Clin Immunol. 2000;105:541546.

18. Gosswein T, Kocot A, Emmert G, Kreuz W, Martinez-Saguer I, et al. Mutational spectrum of the C1INH (SERPING1) gene in patients with hereditary angioedema. Cytogenet Genome Res. 2008;121:181-188.

19. Pappalardo E, Cicardi M, Duponchel C, et al. Frequent de novo mutations and exon deletions in the Clinhibitor gene of patients with angioedema. J Allergy Clin Immunol. 2000;106:1147-1154.

20. Rosen FS, Charache P, Pensky J, Donaldson VH. Hereditary angioneurotic edema: Two genetic variants. Science. 1965;148:957-958.

21. Verpy E, Couture-Tosi E, Eldering E, Lopez-Trascasa M, Spath P. Crucial residues in the carboxy-terminal end of $\mathrm{C} 1$ inhibitor revealed by pathogenic mutants impaired in secretion or function. JCI. 1995;95: 350-359.

22. Dill KA, Chan HS. From Levinthal to pathways to funnels. Nat Struct Biol. 1997;4:10-19.

23. Ellgaard L, Helenius A. Quality control in the endoplasmic reticulum. Nat Rev Mol Cell Biol. 2003;4:181-191.

24. Rosen FS, Alper CA, Pensky J, Klemperer MR, Donaldson VH. Genetically determined heterogeneity of the $\mathrm{C} 1$ esterase inhibitor in patients with hereditary angioneurotic edema. JCI. 1971;50:2143-2149.

25. Wagenaar-Bos IG, Hack CE. Structure and function of C1-inhibitor. Immunol Allergy Clin North Am. 2006;26:615-632.

26. Lachmann PJ, Rosen FS. The catabolism of C1-inhibitor and the pathogenesis of hereditary angio-edema. Acta Path Microbiol Scand. 1984; 92:35-39.

27. Quastel M, Harrison R, Cicardi M, Alper CA, Rosen FS. Behavior in vivo of normal and dysfunctional $\mathrm{C} 1$ inhibitor in normal subjects and patients with hereditary angioneurotic edema. JCI. 1983;71:1041-1046.

28. Donaldson VH, Ratnoff OD, Da Silva WD, Rosen FS. Permeabilityincreasing activity in hereditary angioneurotic edema plasma. II. Mechanism of formation and partial characterization. JCI. 1969;48:642-653.

29. Donaldson VH, Rosen FS, Bing DH. Role of the second component of complement (C2) and plasmin in kinin release in hereditary angioneurotic edema (H.A.N.E.) plasma. Trans Assoc Am Physicians. 1977;40: 174-183.

30. Curd JG, Prograis L Jr, Cochrane CG. Detection of active kallikein in induced blister fluids of hereditary angioedema patients. J Exp Med. 1980;152:742-747.

31. Curd JG, Yelvington M, Burridge N, et al. Generation of bradykinin during incubation of hereditary angioedema plasma [abstract]. Presented at the IXth International Complement Workshop, November 21-25, 1981, Key Biscayne, Florida. Mol Immunol. 1982;19:1365.

32. Fields T, Ghebrehiwet B, Kaplan AP. Kinin formation in hereditary angioedema plasma: evidence against kinin derivation from $\mathrm{C} 2$ and in support of "spontaneous" formation of bradykinin. J Allergy Clin Immunol. 1983;72:54-60.

33. Lammle B, Zuraw BL, Heeb MJ, Schwarz HP, Berrettini M, Curd JG, Griffin JH. Detection and quantitation of cleaved and uncleaved high molecular weight kininogen in plasma by ligand blotting with radiolabeled plasma prekallikrein or factor XI. Thromb Haemostas. 1988;59: 151-161.

34. Berrettini M, Lammle B, White T, Heeb MJ, Schwarz HP, Zuraw B, Curd J, Griffin JH. Detection of in vitro and in vivo cleavage of high molecular weight kininogen in human plasma by immunoblotting with monoclonal antibodies. Blood. 1986;68:455-462.

35. Schapira M, Silver LD, Scott CF, Schmaier AH, Prograis LJ Jr, Curd JG, Colman RW. Prekallikrein activation and high- molecular-weight kininogen consumption in hereditary angioedema. $N$ Engl J Med. 1983; 308:1050-1054.

36. Nussberger J, Cugno M, Amstutz C, Cicardi M, Pellacani A, Agostoni A. Plasma bradykinin in angio-oedema. Lancet. 1998;351:1693-1697.

37. Zuraw BL, Lammle B, Sugimoto S, Griffin JH, Curd JG. Cleavage of high molecular weight kininogen in plasma during attacks of angioedema in hereditary angioedema [abstract]. Presented at the $43^{\text {rd }}$ Annual Meeting of the American Academy of Allergy and Immunology, Washington, D.C. J Allergy Clin Immunol. 1987;79:177.

38. Shoemaker LR, Schurman SJ, Donaldson VH, Davis AE. Hereditary angioneurotic oedema: characterization of plasma kinin and vascular permeability-enhancing activities. Clin Exp Immunol. 1994;95:22-28.

39. Han ED, MacFarlane RC, Mulligan AN, Scafidi J, Davis AE 3rd. Increased vascular permeability in $\mathrm{C} 1$ inhibitor-deficient mice mediated by the bradykinin type 2 receptor. J Clin Invest. 2002;109:1057-1063.

40. Zuraw BL, Christiansen SC. New promise and hope for treating hereditary angioedema. Expert Opin Investig Drugs. 2008;17:697-706.

41. Bork K, Frank J, Grundt B, Schlattmann P, Nussberger J, Kreuz W. Treatment of acute edema attacks in hereditary angioedema with a bradykinin receptor-2 antagonist (Icatibant). J Allergy Clin Immunol. 2007;119:1497-1503.

42. Byrd JB, Adam A, Brown NJ. Angiotensin-converting enzyme inhibitorassociated angioedema. Immunol Allergy Clin North Am. 2006;26:725737.

43. Brown NJ, Byiers S, Carr D, Maldonado M, Warner BA. Dipeptidyl peptidase-IV inhibitor use associated with increased risk of ACE inhibitor-associated angioedema. Hypertension. 2009;54:516-523.

44. Adam A, Cugno M, Molinaro G, Perez M, Lepage Y, Agostoni A. Aminopeptidase $\mathrm{P}$ in individuals with a history of angio-oedema on ACE inhibitors. Lancet. 2002;359:2088-2089.

45. Drouet C, Desormeaux A, Robillard J, Ponard D, Bouillet L, et al. Metallopeptidase activities in hereditary angioedema: effect of androgen prophylaxis on plasma aminopeptidase P. J Allergy Clin Immunol. 2008;121:429-433.

46. Leeb-Lundberg LM, Marceau F, Muller-Esterl W, Pettibone DJ, Zuraw BL. International union of pharmacology. XLV. Classification of the kinin receptor family: from molecular mechanisms to pathophysiological consequences. Pharmacol Rev. 2005;57:27-77.

47. Lung CC, Chan EKL, Zuraw BL. Analysis of an exon 1 polymorphism of the B2 bradykinin receptor gene and its transcript in normal subjects and C1 inhibitor deficient patients. JACI. 1997;99:134-146.

48. Freiberger T, Vyskocilova M, Kolarova L, et al. Exon 1 polymorphism of the B2BKR gene does not influence the clinical status of patients with hereditary angioedema. Hum Immunol. 2002;63:492-494.

49. Brull D, Dhamrait S, Myerson S, Erdmann J, Woods D, et al. Bradykinin $\mathrm{B} 2 \mathrm{BKR}$ receptor polymorphism and left-ventricular growth response. Lancet. 2001;358:1155-1156.

50. Van Guilder GP, Pretorius M, Luther JM, Byrd JB, Hill K, Gainer JV, Brown NJ, et al. Bradykinin type 2 receptor BE1 genotype influences bradykinin-dependent vasodilation during angiotensin-converting enzyme inhibition. Hypertension. 2008;51:454-459.

51. Bossi F, Fischetti F, Regoli D, Durigutto P, Frossi B, et al. Novel pathogenic mechanism and therapeutic approaches to angioedema associated with C1 inhibitor deficiency. J Allergy Clin Immunol. 2009;124: 1303-10.e4.

52. Sandoval R, Malik AB, Minshall RD, Kouklis P, Ellis CA, Tiruppathi C. $\mathrm{Ca}(2+)$ signalling and PKCalpha activate increased endothelial permeability by disassembly of VE-cadherin junctions. $J$ Physiol. 2001;533(Pt 2):433-445. 